\title{
Teoria da Subjetividade: Um caminho para a compreensão da conjugalidade e de seus processos individuais e sociais expressados na psicoterapia
}

\begin{abstract}
Valéria Deusdará Mori' e Helena Abdalla ${ }^{1}$
${ }^{1}$ Departamento de Psicologia e Saúde do Centro Universitário de Brasília-UniCEUB, Brasil morivaleria@gmail.com; helena.abdalla@gmail.com | https://orcid.org/0000-0002-5215-

5472; https://orcid.org/0000-0002-2414-3765

Resumo: A Psicologia como ciência compreendeu a subjetividade, essencialmente e simultaneamente, como um processo individual que determina todos os outros processos e também meramente social, sendo o homem determinado por ela. A subjetividade é produzida historicamente e não um resultado direto dos processos que vivemos nos espaços que compartilhamos. O objetivo do presente artigo é explicar a psicoterapia de casal como um cenário favorecedor para compreensão dos processos subjetivos individuais e sociais, implicados na conjugalidade. Esses aspectos evidenciam-se de acordo com a Teoria da Subjetividade em uma perspectiva histórica e cultural. E a Epistemologia Qualitativa, na qual se apoia a pesquisa construtivo-interpretativa orientando os processos metodológicos desta pesquisa. Realizada em um consultório particular com um casal, cujas ferramentas utilizadas são o diálogo e complemento de frases. Constatou-se que os processos de desenvolvimento subjetivo apresentados na relação conjugal, se organizam em configurações subjetivas complexas e contraditórias. Os sentidos subjetivos decorrentes do sistema individual e social, referentes às histórias de vida singulares e às características da subjetividade social brasileira perpassam, de forma mútua, pela singularidade de cada pessoa e são expressados pelo caráter dialógico do espaço psicoterapêutico.
\end{abstract}

Palavras-chave: Subjetividade; Psicoterapia; Dialogicidade; Conjugalidade.

Subjectivity Theory: A Way to Understand Conjugality and Its Individual and Social Processes Expressed in Psychotherapy

\begin{abstract}
Psychology as a science understood subjectivity, essentially and simultaneously, as an individual process that determines all other processes and also merely social, being the man determined by it. Subjectivity is historically produced and not a direct result of the processes we live in the spaces we share. The purpose of this article is to explain couple psychotherapy as a favorable scenario for understanding the individual and social subjective processes, implicated in conjugality. These aspects are evidenced in accordance with the Theory of Subjectivity in a historical and cultural. And Qualitative Epistemology, on which constructive-interpretive research is supported, guiding the methodological processes of this research. Held in a private practice with a couple, whose tools used are dialogue and complement of phrases. It was found that the subjective development processes presented in the marital relationship are organized in complex and contradictory subjective configurations. The subjective meanings arising from the individual and social system, referring to the singular life stories and the characteristics of Brazilian social subjectivity, cross, mutually, through the uniqueness of each person and are expressed by the dialogic character of the psychotherapeutic space.
\end{abstract}

Keywords: Subjectivity; Psychotherapy; Dialogism; Conjugality.

\section{Introdução}

A organização da história da vida conjugal e familiar brasileira só pode ser compreendida levando-se em conta a diversidade étnica e cultural do país e os paradoxos que incluem tal diversidade, nos projetos políticos e sociais. Como bem afirmam González Rey e Mitjáns Martínez (2017), o posicionamento de cada membro não tem um valor em si dentro da família, pois depende de seu lugar nas configurações subjetivas sociais que caracterizam os diferentes processos e sistemas de relação da mesma. 
A sociedade contemporânea tem enfrentado uma contradição: a superficialidade das relações conjugais que leva ao conflitante desejo de tornar a relação mais profunda e intensa e, ao mesmo tempo, deixá-la solta. No atual contexto cultural ela se torna durável enquanto houver satisfação suficiente. Elementos significativos que possibilitam sustentar uma relação a longo prazo, como a qualidade de um diálogo que favoreça discussões importantes para a manutenção da relação, têm sido percebidos como algo desgastante e desnecessário, tendo em vista a facilidade do rompimento e a busca incessante pelo prazer como bem maior.

Os modelos de casamento no Brasil, desde a colonização até os dias atuais, ainda têm raízes profundas em alguns aspectos como, por exemplo, o patriarcalismo que implica em relações caracterizadas pela autoridade imposta do homem sobre a mulher e filhos, relacionamentos marcados pela dominação e controle, que se traduzem na ausência de comunicação, negociação e interesses em comum. Em contrapartida, devido aos atuais valores individualistas que sugerem relacionamentos com mais liberdade e felicidade, enfatiza-se de forma imperativa a independência e satisfação de cada cônjuge em primeiro plano, fazendo com que outro paradoxo se evidencie. Não há casamento se não houver a criação de uma zona comum de interação, de troca, de uma identidade conjugal (FéresCarneiro \& Ziviani, 2010).

$\mathrm{Na}$ Teoria da Subjetividade a psicoterapia não é um trabalho individualizado. Caracterizase como um movimento dialógico orientado para a mobilização de diferentes processos subjetivos, individuais e sociais. Envolve uma multiplicidade de elementos que requer a compreensão não somente da estrutura familiar e seus processos interacionais, como também a compreensão de outros processos da sociedade tensionados a partir do diálogo e evidenciados de forma indireta na narrativa dos indivíduos. Como expressa Mori (2019, p.9) "os fenômenos da psicoterapia têm importância para a visualização dos processos subjetivos tanto individuais como sociais possibilitando seu estudo com base nos processos de comunicação do qual participam diferentes pessoas em processos singulares de subjetivação".

O desafio da psicoterapia de casal na perspectiva da Teoria da Subjetividade é compreender a complexidade de outros importantes elementos que estão envolvidos na relação conjugal. O profissional não deve se ater apenas aos fenômenos cotidianos que o casal revela, queixas e comportamentos inadequados e sim, refletir criticamente sobre os processos complexos que perpassam a conjugalidade. Quando o casal não compreende e não dialoga sobre outros aspectos da vida, atrelados ao casamento, como elementos históricos e culturais, eles tendem a ficar na bidirecionalidade, ou seja, visualizando a relação por apenas duas direções: a história do marido e a história da mulher. Organizando-se num processo de vitimização, rivalidade e ou competitividade, que constituem a forma como eles subjetivam um ao outro e à própria relação. Sair da lógica do certo ou do errado, de um ser culpado e o outro vítima demanda uma complexidade reflexiva, intrinsecamente relacionada às construções sociais e seus discursos.

O artigo aqui proposto busca contribuir para o campo da Psicologia, bem como para a prática da psicoterapia de casal, pela perspectiva da Teoria da Subjetividade. Pois, se insere no esforço para construir um modelo teórico que vise a uma nova compreensão dos processos da vida conjugal, proporcionando caminhos alternativos para a prática do psicoterapeuta e para os próprios indivíduos da relação.

\section{A Concepção da Psicoterapia pela Teoria da Subjetividade}

$\mathrm{Na}$ busca por mudanças, a prática da psicoterapia vem sofrendo consequências e impactos decorrentes de uma concepção centrada somente na trama e história singular do indivíduo e suas relações de causalidade. Não envolvendo e abrangendo a complexidade e as contradições dos processos da subjetividade em seus múltiplos contextos atuais. 
Esse espaço esteve por muito tempo vinculado à técnicas científicas resultantes do pensamento moderno ocidental, no sentido de tornar-se ciência, adotando um movimento de padronização e quantificação como sendo o único critério confiável para diferentes análises do humano. Contexto que dificulta aos psicoterapeutas o mergulho em reflexões sobre uma visão mais ampla e multifacetada do desenvolvimento humano, que abrange aspectos histórico-culturais relevantes para a compreensão do indivíduo e a maneira como se organiza nos diferentes âmbitos sociais que participa. O modelo positivista e instrumental, que ainda influencia a Psicologia, confronta a pesquisa empírica ao processo teórico, levando a uma divisão entre eles.

"O desconhecimento dos psicólogos sobre os avanços e críticas feitos no interior da psicologia ao positivismo e ao uso puramente instrumental da quantificação revela a orientação ateórica que domina a disciplina até os dias de hoje e da qual deriva uma profunda subestimação das questões históricas, culturais e filosóficas, mesmo daquelas que são inseparáveis do próprio desenvolvimento da área." (González Rey \& Mitjáns Martínez 2017, p.10)

Importante ressaltar a diferença entre a Psicologia como ciência e a psicoterapia como uma prática que a fundamenta. "Portanto, o campo da psicoterapia expressa as diferentes contradições da própria conformação da psicologia como ciência" (Mori, 2020, p.200). Por conseguinte, refletir sobre a formação dos psicoterapeutas requer uma revolução na maneira de pensar, assumindo uma posição distinta à cultura da instrumentalização e sobre o que de fato as técnicas e ferramentas representam teoricamente.

\subsection{Psicoterapia e Subjetividade: Avançando nos Conceitos dessa Proposta}

A psicoterapia deve ser um espaço que está para além de técnicas e que seja facilitador do desenvolvimento subjetivo do outro, ou seja, abrir caminhos de reflexão crítica sobre os processos humanos em seus contextos sociais.

A subjetividade é um sistema dinâmico e complexo, que supera com toda lógica de linearidade presente nas concepções racionalistas e deterministas da compreensão dos processos humanos. Ao reconhecer que a subjetividade é uma produção humana, as emoções passam a ter um lugar diferenciado nisso, não mais como algo trivial ou como epifenômenos de outros processos. Entendemos a existência do indivíduo e o admitimos como alguém gerador de processos emocionais.

Ela se organiza em unidades simbólico-emocionais, chamadas de sentidos subjetivos, que nunca aparecem diretamente significados pelas palavras. Unidades que estabelecem a articulação entre pensamentos, emoções e ações, ou seja, acompanham o caráter dinâmico e vivo das experiências humanas.

González Rey e Mitjáns Martínez (2017, p.63) apresentam:

"Os sentidos subjetivos emergem no curso da experiência, definindo o que a pessoa sente e gera nesse processo, definindo a natureza subjetiva das experiências humanas. Esse novo tipo de processo emerge na vida social culturalmente organizada, permitindo a integração do passado e do futuro como qualidade inseparável da produção subjetiva atual".

A ação do psicoterapeuta se traduz no outro pela maneira como ele interpreta aquilo que é falado, pela maneira como ele sente e como as diferentes emoções tomam forma na experiência da psicoterapia. Pensar a psicoterapia é sensibilizar o indivíduo a estar ativo e imerso em suas experiências tornando-se importante compreender como as tramas sociais e os diferentes discursos estão configurados subjetivamente no decorrer da psicoterapia.

A configuração subjetiva, outra categoria importante definida por González Rey, (2011), é aquela que abarca a diversidade e complexidade dos cenários sociais da vida do indivíduo por meio de sentidos subjetivos, destacando-se seu caráter não racional. 
"A configuração subjetiva permite identificar uma produção dominante de sentidos subjetivos que não aparece explícita nem na queixa da pessoa, nem em sua rotina de ações, pois é um tecido simbólico-emocional complexo que aparece indiretamente nas expressões da pessoa e que está na base do tipo de emoções que prejudicam os sistemas somático-funcionais da pessoa" (González Rey, 2011, p.37).

O indivíduo está envolvido permanentemente em suas ações que, ao mesmo tempo, são produções subjetivas. Ele não é refém de sua subjetividade podendo tornar-se sujeito dela o que determina um processo ativo na tomada de medidas que são fontes geradoras de sentidos subjetivos. Assim, emergir como sujeito é parte essencial da mudança de configurações dominantes no modo de viver uma experiência.

O sujeito caracteriza-se pela capacidade do indivíduo de se posicionar frente às questões referentes aos espaços sociais inserido. Porém, mais do que isso, segundo González Rey e Mitjáns Martínez (2017) significa a abertura de um caminho próprio de subjetivação que pode ultrapassar esses espaços, os quais atuam de forma inovadora, produtiva e criativa. É a habilidade de originar e estabelecer através de seus posicionamentos recursos subjetivos que estão, muitas vezes, distantes de sua consciência. Iniciar um caminho próprio de subjetivação se traduz em uma mudança de vida e, sobretudo, em sustentar ao longo do tempo esse novo posicionamento.

O psicoterapeuta precisa estar aberto à diversidade do humano, tendo como finalidade estimular no outro reflexões, ações criativas e alternativas aos processos sociais hegemônicos, focando na qualidade da relação, para que ele possa pensar sobre a maneira como se vê e se reconhece em sua própria história.

A partir do caráter dialógico retratado por Mori e Goulart (2019), definiremos o diálogo, como ferramenta fundamental, para a mudança do indivíduo em psicoterapia. É por meio da qualidade dele que o psicoterapeuta passará a desenvolver ideias, reflexões e recursos a fim de expandir processos que façam sentido para o outro. Assim, facilita o levantamento de hipóteses e instiga a pessoa a pensar sobre seus processos de vida

\subsection{Os Processos da Subjetividade Social e Individual Presentes na Conjugalidade}

A subjetividade presente nessa proposta, compõe-se em dois níveis diferentes, a subjetividade individual e a social, os quais se constituem mutuamente, expressados em sistemas diferentes e estreitamente relacionados em suas configurações subjetivas. Os processos sociais deixam de ser vistos como algo externo ao indivíduo, tendo em vista que a subjetividade social é uma dimensão complexa do sistema humano. E os sentidos subjetivos de cada um desses níveis está intimamente organizado no outro, como uma produção singular. (González Rey \& Mitjáns Martínez, 2017)

As pessoas manifestam e exprimem processos da sociedade em que vivem por meio de sentidos subjetivos produzidos pela configuração subjetiva individual de suas vivências. Existem aspectos sociais que notoriamente aparecem nas expressões dos indivíduos.

Nessa lógica, González Rey e Mitjáns Martínez (2017, p.84) ressaltam que:

"A subjetividade social da família não está dada, assim como nenhuma das formas de subjetividade social, por elementos gerais que caracterizam o funcionamento aparente da família mas, sim, pelas configurações subjetivas sociais e individuais que a integram e pela maneira pela qual discursos, valores e outras produções sociais emergem nessas configurações. $O$ posicionamento de cada indivíduo não tem um valor em si mesmo dentro da família. Sua acolhida dependerá de seu lugar nas configurações subjetivas sociais que caracterizam os diferentes processos e sistemas de relação na família". 
Entender a subjetividade social e seus processos no contexto da conjugalidade está para além de recodificar as mensagens trazidas, através do seu sistema conversacional e de centrar-se no problema e seus sintomas. Os sintomas são indissociáveis de uma história de vida e de um conjunto de relações nos diversos âmbitos que os indivíduos participam. Não se pode reduzir a conjugalidade a um sistema de crenças de origem familiar, marcado apenas pela continuidade geracional. É necessário refletir sobre outros aspectos históricoculturais, que perpassam os indivíduos de uma maneira que não reconhecem, mas que se organizam historicamente em configurações subjetivas individuais, que darão origem à configuração subjetiva do casal.

A construção de um casamento requer a criação de um espaço comum de interação, de uma identidade conjugal. A contemporaneidade tem sido marcada por forças contraditórias pois, por um lado as ideias egoístas estimulam a autonomia dos cônjuges, enfatizando que o casal deve apenas sustentar e providenciar o desenvolvimento de projetos individuais. Em contrapartida, emerge a necessidade de vivenciar a conjugalidade, a realidade comum do casal, sonhos, desejos e propósitos (Féres-Carneiro \& Ziviani, 2010).

Frente a isso, há um desafio sobre como os indivíduos envolvidos no casamento, organizados em diferentes configurações subjetivas individuais, podem avançar e amadurecer no processo da relação. Abrindo novos caminhos subjetivos e desenvolvendo recursos, ou seja, produzindo simbólica e emocionalmente outro caminho subjetivo na busca de alternativas que promovam saúde e bem estar para a conjugalidade, as quais podem transpor as representações dominantes da subjetividade social.

Os indivíduos são afetados por questões que dizem respeito a configurações subjetivas sociais hegemônicas, que acompanham a história de uma cultura. Como o egoísmo, o controle, o patriarcalismo, a vitimização, o imediatismo, o consumismo, a ausência de diálogo, a romantização das relações amorosas. Eles não se vinculam, fundamentalmente, com o problema da relação. Mas, sim, com as características referentes à subjetividade social.

"Um relacionamento amoroso não existe na sequência de atos e situações objetivas vividos de forma conjunta, mas como uma configuração subjetiva através da qual tomam vida na relação do casal sentidos subjetivos que respondem a desdobramentos biográficos, cada um deles emergindo, conjunturalmente, nas situações do relacionamento e se integrando a expressões que parecem ser o resultado do aqui e agora da relação. Porém, os sentidos subjetivos das configurações subjetivas atuais da vida de um casal não podem ser buscados apenas na história do relacionamento desse casal, o que é geral no estudo de qualquer sistema subjetivo" (González Rey, 2011, p.35).

Cada membro de uma família é uma parte constituída de configurações da subjetividade social em que está inserido, trazendo ao nível de comportamento e de contradições esses múltiplos espaços sociais que participa para o espaço familiar. Compreender os indivíduos envolvidos na conjugalidade é necessariamente estudar e compreender o social.

\section{Metodologia: Epistemologia Qualitativa e seus Pressupostos}

A Epistemologia Qualitativa proposta por González Rey (1997, 2005, 2017), na qual se apoia a pesquisa construtivo-interpretativa, orienta os processos metodológicos desta pesquisa. A pesquisa qualitativa é uma realização autoral. Um processo de contínua construção de uma produção teórica, ou seja, um conhecimento que é produzido no decorrer da própria pesquisa. Ela caracteriza-se pela construção de um modelo teórico que expressa as ideias e construções do pesquisador, dentro de um conjunto ilimitado e inacabável de expressões, que tomam sentido no contexto em que aparecem, um processo que demanda entrega e dedicação. 
O primeiro pressuposto, da Epistemologia Qualitativa, é o reconhecimento do valor da singularidade. $O$ singular caracteriza-se como informação diferenciada que se fundamenta no caso específico e que toma significado em um modelo teórico. O caráter construtivointerpretativo, o segundo pressuposto, preserva a ideia do conhecimento como uma produção e não uma adequação linear da realidade ou uma reprodução do saber, rompendo com a dicotomia entre teoria e prática.

Segundo González Rey e Mitjáns Martínez (2017), para que o envolvimento ocorra é indispensável, no desdobramento da pesquisa, a comunicação dialógica, terceiro pressuposto. As informações são geradas nesse sistema conversacional, o que permite um processo construtivo daqueles que participam, implicando em contradições, rupturas, abertura de caminhos e novas produções subjetivas.

\subsection{Participantes}

Maria e João, nomes fictícios, têm acima de trinta e cinco anos de idade, casados há mais de sete anos e não têm filhos. Maria é graduada em Direito, trabalha como advogada e João não possui nível superior completo, trabalha em uma companhia aérea.

\subsection{Instrumentos}

Os instrumentos empregados na presente pesquisa foram: sistemas conversacionais, complemento de frases como "o que me faz feliz e infeliz no casamento e "eu desejo".

\section{Caso Maria e João: Analisando e Construindo Informações}

A expectativa inicial de Maria, no processo psicoterapêutico, era trabalhar características que considerava como prejudiciais para si e para suas relações como: ciúme excessivo, sentimento de posse sobre o outro, dificuldade de sustentar suas relações com amigos, dificuldade em dizer não e colocar limites.

Pesq: O que te marcou na sua relação familiar?

M: Meu avô. Além de privar minha mãe até hoje, sempre me privou muito. Não podia sair de casa, encontrar as amigas, ir às festinhas. Era rígido e controlador.

É pertinente pensar em indicadores sobre a produção subjetiva do masculino na história de Maria, como uma figura forte e de autoridade. Não sendo a responsável a priori pelo seu comportamento mas, que se organizaram pelos sentidos subjetivos que emergiram no decurso das situações vividas.

Meu maior medo morrer e deixar as pessoas que dependem de mim sem apoio.

Sofro por ver os outros sofrendo.

Meu futuro é incerto.

Algumas vezes penso que seria melhor ter nascido outra pessoa.

No complemento de frases acima, percebemos que, sentidos subjetivos que se organizam de forma contraditória, como cuidado e o controle que vão tomando conta de sua vida em outros âmbitos sociais. O maior medo de Maria é deixar as pessoas que dependem dela sem apoio, ou seja, ela vive pelo outro, não se reconhece e não consegue se envolver como sujeito em relação ao seus processos de vida, que passam a não ter sentido. 
Pesq: João, me fale sobre você.

J: Pulei muitas etapas da vida e abri mão de coisas importantes. Nunca consegui expressar minha opinião com minha mãe e sempre concordava para não brigarmos. Ela nunca acreditou nos meus sonhos. Sonhava em ser piloto de avião.

João trabalha em uma companhia aérea. Criado por sua mãe, uma mulher batalhadora, precisou ausentar-se bastante de casa, dia e noite, a fim de proporcionar o melhor para seu filho.

O trecho de informação acima, unido a outros, são indicadores expressados por meio de sentidos subjetivos de solidão e sentimento de desamparo produzidos por ele, tornando-o preso ao passado e conduzindo-o a um caráter passivo diante de seu cenário de vida atual, submetendo-se e conformando-se com a vida que leva. Em princípio, observa-se a incapacidade de João para tomar decisões que the permitam interromper esse processo.

$\mathbf{J}$ : Preciso criar uma identidade. E nós não podemos continuar como somos. Maria teve um avô controlador e eu entendo sua história, seu jeito e não a culpo.

Pesq: Maria, como é ouvir seu marido?

M: Sei que exagero. É um controle excessivo que está me fazendo mal. É difícil não controlar porque fui criada assim. $E$ João era mais passivo antes.

Apesar de Maria ter consciência de suas ações, o que é bastante significativo, a forma como ela configura sua relação com João é uma maneira de subordiná-lo aos seus critérios de vida. Nota-se, em sua narrativa, uma enorme contradição pois, apesar de reconhecer a nocividade de suas ações, há uma enorme dificuldade em aceitar a mudança de João.

João, ao reconhecer as inseguranças de Maria, expressa sua dificuldade em se posicionar e reproduz no casamento sua própria história de vida. Percebe-se como a configuração subjetiva da família de origem tem sentidos subjetivos que estão atrelados à configuração atual do casamento. O medo de João de desagradar e gerar pânico é indicador da dificuldade para gerar posicionamentos novos em sua rotina.

Pensamos, então, na existência de uma configuração subjetiva dominante em sua vida, sua relação com sua mãe. A configuração subjetiva do casamento é marcada pelo controle. Sentidos subjetivos de medo, frustração e conformismo passam a fazer parte de processos da subjetividade individual, tensionando outros diferentes processos sem que eles tenham consciência. O que dificulta a abertura de caminhos individuais.

Pesq: João, você disse que seu sonho era ser piloto, é isso mesmo?

J: Sim. Mas, se eu voar vou me distanciar de casa e Maria não quer.

M: (Exaltada) Realmente não dará certo! Não mando na vida dele mas, não garanto que ficará tudo bem.

No trecho acima, há uma ameaça velada. Maria disfarçadamente diz que se João optar por seguir seu sonho ela o abandona. Ao mesmo tempo, João complementa Maria em suas ações se posicionando passivamente na relação como alguém que precisa ser cuidado e que necessita de um responsável. Os sentidos subjetivos mobilizados dentro do casamento são históricos, tem a ver com a história de vida de cada um. Por exemplo, João em sua história familiar, nunca teve coragem de enfrentar sua mãe, ficava calado diante das decisões dela para evitar conflitos, mantendo-se subordinado e conformado a um cenário onde sua mãe não tinha tempo para ele e não dava as orientações que gostaria. Diante de configurações subjetivas individuais distintas, João sente a necessidade de Maria para sua segurança e Maria sente a necessidade de João para se sentir ela mesma. 
Pesq: Gostaria que escrevessem o que os faz felizes e infelizes no casamento.

M: Reconhecer o que faço de bom

Gostar de mim como eu sou;

Se preocupar comigo;

Não pensar, ser imediatista;

Colocar as prioridades dele à frente de tudo.

Maria gosta do fato de João estar subordinado a ela, como ela mesma escreveu na dinâmica, não quer que ele mude, quer que ele continue gostando dela do jeito que é. Assim aprendeu a operar na vida, ao mesmo tempo que tem um marido que se submete ao seu controle e que a aceita do seu jeito, ela não admira isso tornando-se incoerente.

J: Saber que qualquer decisão exceto comissário ou piloto ela estará ao meu lado

Gosto de cuidar dela

Saber que ela gosta de cuidar de mim

Não cuida de sua saúde

Nao deixa eu fazer aquilo que me sinto bem

João não tem consciência que a centralidade de Maria é a expressão de algo muito mais complexo e profundo que é o seu próprio mundo afetivo. E ainda não tem força para construir seu próprio caminho. Os sentidos subjetivos decorrentes da configuração subjetiva do vínculo com sua mãe são responsáveis pelo espaço em que Maria vai ocupando. Sua procura por orientação, aceitação e decisão do outro, que não lhe permite tomar decisões importantes, são encontradas em sua relação conjugal.

A subjetividade individual de João está configurada numa perspectiva de passividade, em que ele se subordina aos critérios do outro para viver uma relação feliz. Isso fala sobre a subjetividade social brasileira, em que as pessoas pouco entram em contato com suas próprias contradições, preferindo ficar conformadas com o que lhes é imposto. Negligenciando caminhos importantes a serem tomados a terem que enfrentar frontalmente seus limites, suas circunstâncias e o outro.

A configuração da subjetividade social do casamento dificulta, muitas vezes, o crescimento individual que impossibilita a abertura de um caminho próprio de subjetivação. Após alguns meses o complemento de frases "eu desejo" foi realizada numa sessão.

M: Eu desejo ser mais tolerante

Eu desejo incluir mais amigos na nossa convivência

Eu desejo deixar as coisas do passado menos presentes em nossa vida

J: Eu desejo fazer a vontade um do outro

Eu desejo cuidar um do outro

Eu desejo sair para novos lugares

Cada caminho que é aberto na psicoterapia é uma possibilidade de avançar na representação do problema. A produção de sentidos subjetivos representa um processo infinito que se correlacionam, implicando em novas ações e atitudes nos indivíduos que, mesmo não havendo uma percepção consciente do processo, passam a gerar novos caminhos de vida. Ao serem configurados subjetivamente produzem sentidos subjetivos distintos daqueles que mantiveram os indivíduos numa situação de desconforto. Esses novos sentidos favorecem o empenho deles na relação conjugal, surgindo em seus relatos na dinâmica acima. 
O processo contínuo de diálogo leva o casal a amadurecer suas ideias, ganhando novas possibilidades a cada encontro para se expressarem por meio delas, favorecendo a emergência da subjetividade no decurso desse processo.

\section{Conclusões}

As configurações subjetivas facilitam compreender o mal estar de Maria e João como parte de um processo singular, que aponta para um sistema em andamento e não uma condição dos indivíduos. No decurso da pesquisa de forma gradual, o casal trouxe à tona seus incômodos tensionando os processos sociais. Não terem medo de assumir seus critérios e escolhas a fim de tentarem viver de maneira coerente com seus desejos, implicou na mudança de uma rota, rompendo com a lógica de suas organizações mais estáveis de suas vidas.

O conceito de configuração subjetiva nos permitiu enxergar o mal-estar das pessoas como parte de um processo vivo que representa um sistema em andamento e não uma condição da pessoa. O que demonstra a impossibilidade de falar de um padrão psicológico geral dos indivíduos inseridos na conjugalidade. A psicoterapia no referencial da Teoria da Subjetividade possibilitou o avanço na compreensão do problema estudado, entendendo os processos sociais e individuais, que se constituem mutuamente, com fundamento no caráter dialógico e na singularidade do caso.

O estudo apresenta um modelo teórico em desenvolvimento, construído com o intuito de apoiar práticas profissionais de pesquisa voltadas ao desenvolvimento de casais, capaz de produzir inúmeras inteligibilidades para outros espaços sociais importantes, direcionados à família e suas relações. Tornando-se indispensável outros estudos sobre o tema, apoiados na base da Epistemologia Qualitativa e valorizando sempre seus princípios: a comunicação dialógica, a singularidade do caso e o caráter construtivointerpretativo da produção de conhecimento.

\section{Referências}

Féres-Carneiro, T. \& Ziviani, C. (2010). Conjugalidades Contemporâneas: um estudo sobre os múltiplos arranjos da atualidade. In: Féres-Carneiro, T. (org). Casal e Família: permanências e rupturas. São Paulo: Casa do Psicólogo.

González Rey, F. L. (2011). Subjetividade e Saúde: superando a clínica da patologia. São Paulo: Cortez.

González Rey, F. \& Mitjáns Martínez, A. (2017). Subjetividade: teoria, epistemologia e método. São Paulo: Alínea.

Mori, V. D. (2019). A psicoterapia na perspectiva da teoria da subjetividade: A prática e a pesquisa como processos que se constituem mutuamente. Brasília. UniCeub.

Mori, V. D. (2020). A prática e a pesquisa com base na Teoria da Subjetividade: a psicoterapia como cenário. In: Mítjans Martínez, A., Tacca, M. C. V. R \& Puentes, R. V. Teoria da Subjetividade: discussões teóricas, metodológicas na prática profissional. Campinas, SP: Alínea.

Mori, V. D.. \& Goulart, M. D. (2019) Sujeito e subjetividade na psicoterapia: um estudo de caso. (Subject and Subjectivity within psychotherapy: a case study). In: González Rey, F. \& Martínez, A. \& Goulart (Eds.) Subjectivity within cultural-historical approach: theory, methodology and research. Singapore: Springer. P. 231-244 